\title{
Landslides Caused Deforestation
}

\author{
Diandong Ren ${ }^{1}$, Lance M. Leslie ${ }^{2}$ and Qingyun Duan ${ }^{3}$ \\ ${ }^{1}$ Australian Sustainability Institute, Curtin University, Perth, \\ ${ }^{2}$ School of Meteorology, University of Oklahoma, Norman, \\ ${ }^{3}$ Beijing Normal University \\ ${ }^{1}$ Australia \\ 2USA \\ ${ }^{3}$ People's Republic of China
}

\section{Introduction}

This study investigates landslide caused disturbances to ecosystem-vegetation burial and overturning of soil horizons which can accelerate vegetation loss, or even lead to complete deforestation of the landscape. A summary is presented of the historical development and recent advances in understanding and prediction of landslides/debris flows, which are major global natural hazards that have caused great loss of life and damage to property and infrastructure. The focus here is on rainfall triggered landslides/debris flows, and their deforestation effects. Debris flows have large destructive power because the solid and fluid forces interact within the sliding mass (Iverson 1997): the embedded boulders can exert great impulsive loads on objects they encounter; while the high fluid contents make debris flows travel long distances even in channels with modest slopes and therefore can inundate vast areas. Thus the whole spectrum of debris flows has deforestation effects (even small scale debris flows can denude vegetation). The first two sections of this chapter are concerned, respectively, with understanding ecosystems in terms of their soil and vegetation types, especially in regions that have sloping terrain. The emphasis is on the impact of landslides on deforestation, and this aspect has not yet been studied extensively. The third section focuses on the dynamics of landslides and provides a comprehensive description of their lifecycles, and the fourth section discusses the development and application of empirical and descriptive landslide models. Such models have contributed to knowledge of storm-triggered shallow landslides/debris flows. However, the deficiencies of empirical models are well-known and an alternative modelling technique, pioneered by the first author, is described in detail. This modeling approach is to solve the fully three dimensional, Navier-Stokes, and to that end a multi-rheological scalable, extensible geofluid model modeling system, known as SEGMENT, was developed. When coupled with a landslide model the system is called SEGMENT-landslide. The SEGMENT-landslide model has been used extensively in a predictive mode for both relatively short lead decadal times, and for century long predictions of landslides, in several very different locations. Here, the performance of SEGMENT-landslide is assessed for the Yangjiashan creeping slope in China, in predictive mode for the decade 2010-2109. Investigation of the impact of possible future precipitation morphological changes over this region utilizes 21 st century simulations 
from 17 Climate General Circulation Models. SEGMENT-landslide performed encouraging well in both hindcast and forecast mode, providing prior and future vulnerability of the Yangjiashan creeping slope to landslides and rainfall rate thresholds for sliding to occur. SEGMENT-landslide also has been used to estimate landslide potential in other vulnerable regions, including southern California. Future work will focus on the influence of a future warming on the occurrence of landslides. Knowledge of upcoming changes in precipitation morphology is critical for predicting storm-triggered landslides and desertification. Advanced dynamical models, such as SEGMENT-landslide, which have a physical basis, are needed to supplement documentation of landslide occurrence. As there are biogeochemical submodels coupled in the SEGMENT system, it can be used to investigate significant environmental consequences of landslides, notably deforestation.

\section{Ecosystem of sloping terrain, soil and vegetation}

A unique feature of terrestrial ecosystems is that vegetation acquires its resources from two very different environments; air (for $\mathrm{CO}_{2}$ ) and soil (for inorganic minerals of nutrients). Landslides cause disturbances to ecosystem productivity by displacing the soil mantle. In addition to be the medium in which most decomposer organisms and many animals live, the physical soil matrix provides a source of water and nutrients to plants and microbes and is the physical support system in which terrestrial vegetation is rooted. For these reasons, landslide displacement of the soil mantle has severe ecosystem consequences.

Sloping terrain creates unique patterns of microclimates through surface energy budgets, hydrology and availability of nutrients. For example, slopes facing the equator receiving more solar radiation than opposing slopes and hence usually have warmer and drier conditions. In colder or moister climates, the warmer microclimate of the equator facing slopes provides conditions that enhance productivity, decomposition and other ecosystem processes (including the formation of soils), whereas in dry climates, the low moisture levels on these slopes limits such production. Further, microclimatic variations associated with slope and aspect allows stands of an ecosystem type to exist hundreds of kilometres beyond its major zone of distribution. These outlier populations are important sources of colonizing individuals during times of rapid climate change and are therefore important in understanding species migration and the long-term dynamics of ecosystems. Topography also influences climate through drainage of cold, dense air in the form of katabatic winds, forming strong near surface air temperature inversions. Inversions tend to be strongest at night and during winter, when there is less warming of the surface, either in the form of shortwave solar radiation or longwave thermal from clouds, and hence insufficient convective mixing to remove inversions. Inversions are climatologically important because they increase the seasonal and diurnal temperature extremes experienced by ecosystems in low-lying areas. In cool climates, inversions greatly reduce the length of the frost-free growing season. The third aspect of the impact of sloping surfaces on ecosystems is surface hydrology. The surface runoffs on sloped surfaces are much larger than over flat terrain. For dry climates, this places severe water-limitations on production. Before addressing the slope effects on nutrients, we will review the soil formation process.

Under a given climatic regime, soil properties are the major control over ecosystem processes. Soils are the locality where geological and biological processes intersect. Soils mediate many of the key reactions in the giant global reduction-oxidation cycles of carbon, nitrogen and sulphur, and provide essential resources to biological processes that drive these 
cycles. As the intersection of the bio-, geo- and chemistry in biogeochemistry, soils play such an integral role in ecosystem processes that it is impossible to separate the study of soils from that of ecosystem processes. Soils are formed from weathered metamorphic rocks. The presence of living organisms accelerates the soil formation processes. Water is a pathway for nutrients entering an ecosystem and also is crucial in determining whether the products of weathering accumulate or are lost from a soil, especially the soluble minerals. Top soils generally are more fertile because weathering rates generally are larger at the surface. Also, leaching processes tend to transfer soluble ions (e.g., chelated complexes of organic compounds, iron or aluminium ions from precipitation or released in the weathering of upper layers soil) downwards. During the downward movement, they can react with ions encountered at depth under new chemical environments (e.g., increased $\mathrm{pH}$ value), or may precipitate out the system when dehydration occurs (e.g., water is evaporated in semi-arid or arid climate zones). As a consequence the levels of silica and base cations in the secondary minerals usually increase with depth and result in a nutrient poor deeper soil horizon. As iron and aluminium ions soluted in the soil water move downwards, slight changes in ionic content and the microbial breakdown of the organic matter both can cause the metal ions to precipitate as oxides. The deeper soil horizon containing iron-rich minerals usually are hardened irreversibly. These layers can impede water drainage and root growth. This is the case for tropical iron-rich soils, and similar processes exist for calcium (or magnesium) soils of arid and semiarid temperate climate zones. The hard calcic horizon at depth is formed when calcium carbonate precipitation occurs under conditions of increased $\mathrm{pH}$, or under saturation concentrations of carbonate with evaporation of soil moisture. If debris flows remove the fertile top soils, the deeper horizon is exposed and this layer has poor water retention ability and is nutrient poor. Moreover, roots cannot develop within it and thus cannot support regrowth. Even for the depositional alluvial fans, the exposed deep soil and deep buried top soil forms a nutrient sink for the ecosystem, as the majority of the roots can use nutrients only in the upper one or two meters.

\section{Landslides are double-edged swords}

The surface of the earth, both land and beneath the oceans, is continually being modified by mass movements operating in response to gravitational forces. In this sense, landslides reduce the hill slopes to stable angles. They can assume the form of rockfalls, slumps and slides, and debris flows (Cruden 1991). For this study, the term landslide includes downslope movement over a variety of scales and velocities and also includes those related to vegetation cover. Rainstorms always are the prime cause.

Topography influences soil through its effects on climate and the differential transport of fine soil particles (Amundson and Jenny 1997). Characteristics such as soil depth, texture, and mineral content vary with hillslope position. Erosion processes, such as landslides, preferentially move fine-grained materials downslope and deposit them at lower locations. Depositional areas at the base of slopes and in valley bottoms therefore tend to have deep fine-textured soils with a high soil organic content and high water-holding capacity. These areas also supply more soil resources (water and nutrients) to plant roots and microbes and provide greater physical stability than do higher slope positions. For these reasons alluvial fans at valley bottoms typically exhibit higher rates of most ecosystem processes than do ridges or shoulders of slopes. In brief, soils in lower slope positions have greater soil moisture, more soil organic matter content, and higher rates of nitrogen mineralization and 
gaseous losses than upslope soils (Matson et al. 1991). Therefore, on geological timescales, landslides help produce stable land suitable for agricultural and habitation (for tropical islands, also tourism) and provide materials that form fertile plains and valleys, beaches, and barrier islands. However, on a scale typical of a human life span, the benefits accruing from landslides are overshadowed by their destructive characteristics; they are hazards that should be understood and mitigated as much as possible.

While it is reasonable to generalize that landslide activity is important, landslide impact on deforestation, on ecosystems in general, have not been well addressed. The following comments are not an exhaustive review but are intended to indicate the relevance of landslides to deforestation.

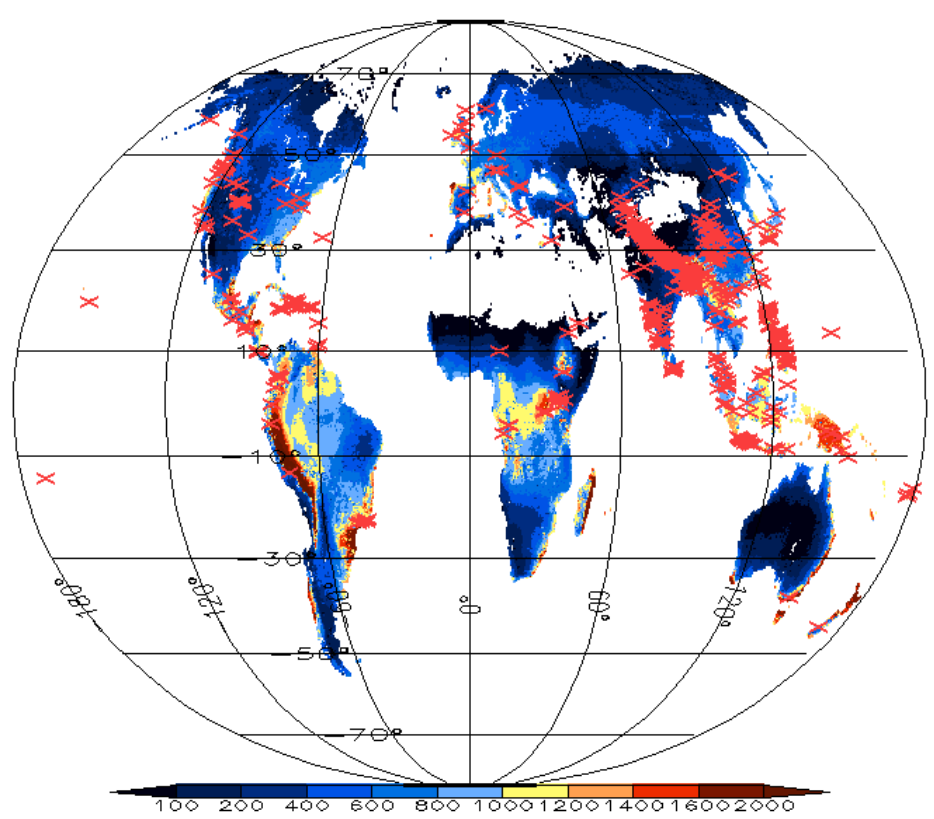

Fig. 1. Global distribution of Net Primary Production (NPP, color shading, in $\mathrm{g} / \mathrm{m}^{2} / \mathrm{yr}$ ) and occurrence (red crosses) of storm-triggered landslides (2003-2007).

The main geological hazards of volcanic activity, earthquakes and landslides are commonly, but not entirely, associated with processes occurring in areas near subduction zones. It is there that elevations are high enough to generate instability and sources of hazardous agents are abundant. This explains why the landslides belt coincides with the Earth's major earthquake belts. The Himalayas, for example is a hot spot (Figure 1). Figure 1 shows the primary landslides that are deeper than $2.5 \mathrm{~m}$ thick and contain $>10^{5} \mathrm{~m}^{3}$ of solid material, enough to cause vegetation damages. Plotted are the cases for years 2003-2007.

Landslides are one type of geological hazard. Geological hazards become so only where population, services or structures are at risk. In this sense, although northwestern China is a hot spot for landslides, the low population, by itself, reduces the hazard to a vanishingly small likelihood. In contrast, India and Indonesia both have large populations under the threat of storm-triggered landslides. It is reported (BNBP, 2009) that during the period 1998- 
2007, 569 landslide events took place in Indonesia which caused 1326 fatilities and around 1500 people missing, around 170,000 people evacuated. In the humid tropics, soil loss after landslides are also very high as soil will be broken and exposed to rainfall wash-resulting in increased sediment load in the streams and causing flooding in low lying areas. As the population of vulnerable regions increases, previously unoccupied alluvial fans are used for habitation (e.g., the Zhouqu county in China) and landslide events therefore have a great potential to impact human settlements or activities.

The state of California in the USA is a locality where the combined effects of earthquakes and landslides have been documented extensively. The precipitation of this region, being regularly affected by ENSO and potentially also sensitive to climate change, has a large uncertainty in the future occurrence of storm-triggered landslides (Ren et al. 2011b).

From Figure 1, there are fewer landslide hazards for regions with $\mathrm{NPP}<200 \mathrm{~g} / \mathrm{m}^{2} / \mathrm{yr}$, indicating that soil, vegetation and landslides are closely tied together in the Earth's environmental system. The landslides free areas occur either because of their limited liquid precipitation (deserts and polar regions) or because of a lack of soil mantle. In both cases, the annual net primary productivity is low.

To evaluate the ecosystem consequence of landslides, it is necessary to know why landslides occur. The possibility of a landslide depends on the balance between the driving forces for downslope movement and the forces that resist this movement. Horizontal stress gradients caused by uneven topography are the drivers of sliding. At the stationary phase, the cohesion between soil particles is the resistive force. Once sliding is initiated, the resistive associated with flow shear is the primary stress that eventually stops the flow.

\section{Landslide dynamics}

Many factors influence the yield strength of a soil mass (Selby 1993). These include the sliding friction between the material and some well-defined plane (i.e., the movement of coarser soil over a saturated clay layer), but most commonly the internal friction caused by the friction among individual grains within the soil matrix. Cohesion among soil particles is sensitive to soil moisture/water content. For sandy soil, a small amount of water enhances cohesion among particles, whereas high water content reduces the frictional strength through increased pore pressure. The situation for clay soil is a simple reduction of strength as moisture content increases. From the perspective of dry internal frictional angle, fineparticle soils have lower slope thresholds of instability and are more likely to lead to slope failure than are coarse-textured soils. The situation is further complicated by hydrological processes and the presence of vegetation (Figure 2).

As illustrated in Figure 2, the presence of aboveground vegetation introduces the following effects: aboveground biomass loading (gravitational), growing season soil moisture extraction by live roots (hydrological), fortification/reinforcement of the soil within its extension range (mechanical), changing chemical environment of the soils and therefore the bonding strength among unit cells (chemical), and wind stress loading (meteorological). The overall effects are an interaction of the above factors and it is difficult to generalize before a detailed analysis is carried out that is specific to a certain situation. For example, the fortifying roots have yield strength larger than dry soils and the existence of roots is commonly thought to increase the resistance of soils. However, the presence of roots, especially when there is precipitation, also facilitates water channelling into deeper depths. 
After the soil is moistened, the cohesion between soil and the root surface is reduced greatly (to negligible strengths $<0.01 \mathrm{Mpa}$ ) and the root strength cannot be effectively exerted. Also, the effect of roots is to 'unify' the soil particles within root distribution range. Once the entire rhyzosphere soil layer is saturated, the fortifying effects will be totally lost. The wind stress and the biomass loading will further deteriorate the situation (e.g., falling trees may join the sliding mass). Therefore, the effects of roots depend on precipitation rates in specific cases and in meteorological conditions in general. The hydrological and chemical effects are not expanded upon here but for interested readers details can be found in Ren et al. (2008, 2011a,b). Here, we provide some details that are highly relevant for 'progressive bulking' type of landslides, such as the pathway by which water leaves the landscape and the erosion ability of running surface water.
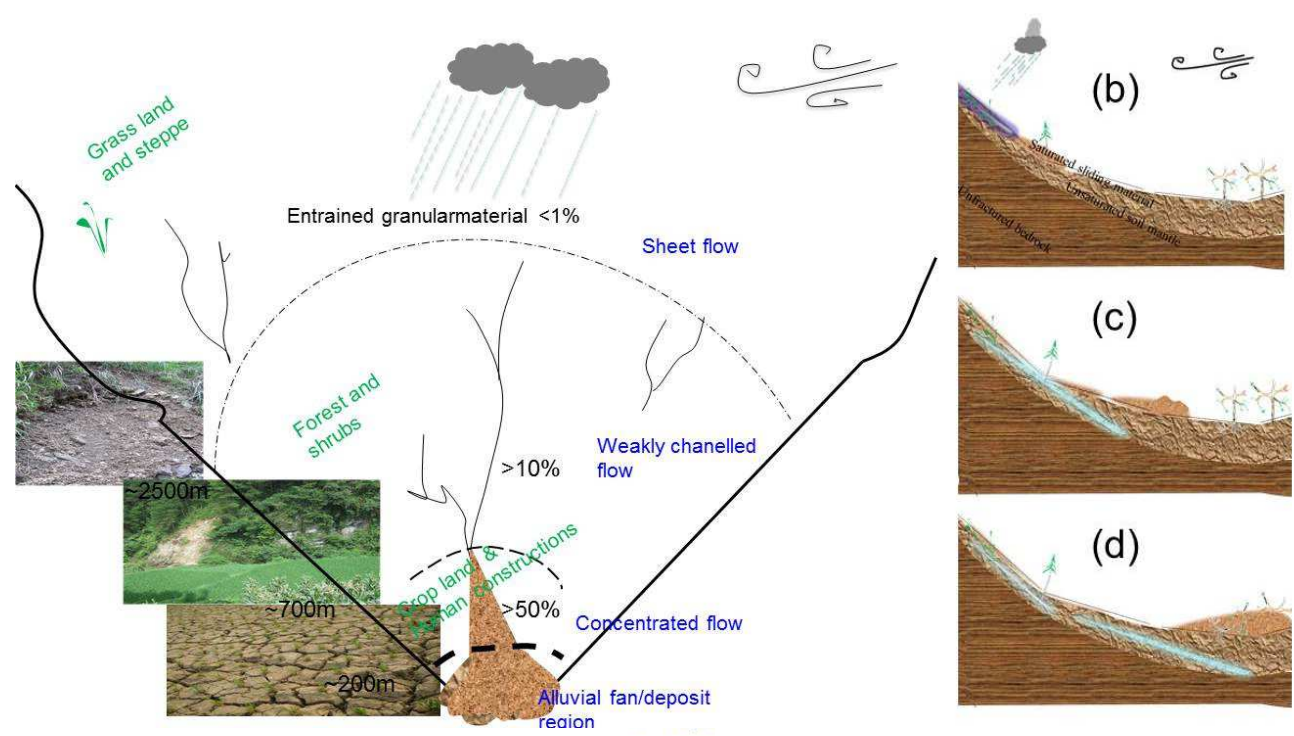

Fig. 2. A characteristic storm-triggered landslide (debris flow). Panel (a) is a plane view of the entire (solid material) collection basin. The elevation divisions are only for reference. The section with concentrated solid material creeping is only a small portion of the entire area. This means of mass redistribution is referred as "progressive bulking". Vegetation mortality is cause by that portion with $>50 \%$ granular material concentration, especially when boulders are entrained. Panels (b), (c) and (d) illustrate a full life cycle of the debris flow: (b) initiation, (c) sliding, and (d) cessation. Precipitation generated surface runoff washes the fine-grained material downslope. Because the steepness of the slope is graded (steep at top and gentler at the toe), granular material (saturated soils) are thicker toward the toe of the slope. As the sliding material run downslope, it entrains the pebbles and small stones (granular material) at the bottom. This will significantly change its rheological properties as it becomes drier and more viscous. The sliding material eventually ceases at places with gentle slopes, or where the slope angle reverses. In the lowest inset panel, the cracked rice paddy is indicative of effects of roots on holding the soil particles together: almost all rice bundles are located at the centers of the cracked cells. Major cracks rarely run directly across a bundle of rice sprouts. 
Water typically leaves a landscape by one of several pathways: groundwater flow, shallow subsurface flow, or overland flow (when precipitation rate exceeds infiltration rate). The relative importance of these pathways is strongly influenced by topography, vegetation, and material properties such as the hydraulic conductivity of soils. Drainage (ground water) and shallow subsurface flow dissolve and remove ions and small particles that cement large soil particles when being dry. Overland flow (runoff) causes erosion primarily by surface sheet wash, rills and rain splash. Runoff is strong for bared ground (e.g., arid soil-mantled landscapes) or disturbed ground (by soil animals or human construction). Runoff of $3 \mathrm{~mm} / \mathrm{s}$ suffices to suspend clay and silt particles and move them downhill (Selby 1993). As water collects in gullies, its velocity, and therefore erosion potential, increases. For clear (not dense) debris flow, erosion potential can be approximated as $a=C_{1}(g h)^{1 / 2} \alpha^{1 / 3}\left(D / D_{0}\right)^{0.27}$, where $C_{1}$ is a coefficient depending on vegetation condition, a is slope, $D$ is particle size and $D_{0}$ is a reference particle size, $h$ is runoff water depth, and $g$ is gravity acceleration.

Vegetation and litter layers level/spread out the peak of runoff and increase infiltration and drainage through reducing velocity with which raindrop hit the soil, thereby preventing surface compaction, and through the inter-connected channels webbed by roots and soil animals. For progressive bulking debris flows, these are apparent preventative features. To evaluate the ecosystem consequence of landslides, we also need to know the size of a landslide. It is apparent that the disturbance of landslides to ecosystem is through displacement of the fertile top soil layer. Whether or not the existing vegetation can be destroyed depends on the severity of the landslide. The severity of a landslide depends on its size, velocity and material composition. The first two points are obvious. The composition of the sliding material is important for landslide destructive potential primarily because the size of granular material. If the debris flow entrained big boulders during its downslope movement, the destructive potential to trees and buildings will be much greater than similar debris flows containing only sands and silts. The drag of debris flows to obstructions can be expressed as $\eta_{\text {eff }} \frac{\partial U}{\partial Z}$, where $U$ is flow speed, $\eta_{\text {eff }}$ is effective dynamic viscosity $(\mathrm{Pa} \bullet \mathrm{s})$. For a fast flow debris flows $(3 \mathrm{~m} / \mathrm{s})$ and $50 \%$ solid material sludge of about 2 meter depth, the stress exerted on obstacles is on the order of $10^{5} \mathrm{~Pa}$. When a large boulder encounters an obstacle, the energy is transformed primarily in the form of longitudinal waves (e.g., similar to acoustic waves in the air). The stress (pressure) impact on the obstacle is $0.5 \rho_{b} U V$, with $V$ the sound wave speed in solids (obstacle medium, at standard pressure of 1 atmosphere and temperature $25{ }^{\circ} \mathrm{C}$, about $4500 \mathrm{~m} / \mathrm{s}$ for bridges and concrete-steel buildings), and $\rho_{b}$ is the boulder's density. In contrast to turbid sludges, a boulder of about 2 $\mathrm{m}^{2}$ cross-sectional area (assuming this also is the area of simultaneous contact with an obstacle), of bulk density of $2.7 \times 10^{3} \mathrm{~kg} / \mathrm{m}^{3}$, can exert $10^{8}$ pa pulse pressure, which is three orders of magnitude larger than the sludge.

Figure 2 is a conceptual sketch of storm-triggered landslides/debris flows. Clearly there is usually a large (one order of magnitude larger than the channelled, streaming, concentrated flows of the dense mud) collection region, providing solid material for the downstream area. Along the flow, the sliding material is denser and viscosity is larger. At the spread region, because of the gained kinetic energy, it will not stop even the slope angle is less than the repose angle. In actuality, it continues to spread until the speed is reduced to zero, usually at bed slopes much smaller than the stable repose angle. In Figure 2, panel (a) is a plane view 
of the mass collecting region, panels (b) to (d) illustrate the life cycle of a debris flow. We see that the solid material is collected by surface runoff from a much larger area than seen with naked eye as mudslide. The portion with direct ecosystem damage primarily is the region with concentrated stream flows, which typically constitutes only about $2 \%$ of the entire collecting area.

The August 8, 2010 Zhouqu landslide is a characteristic 'progressive bulking' type of debris flow. On August 7, Zhouqu's Beishan slope received over $80 \mathrm{~cm}$ of rain within two hours, leading to widespread shallow landslides and debris flow generation. The town of Zhouqu is built on the sloping surfaces of previous debris fans formed at the base of steep rocky hillslopes.

The debris fan at the mouth of the rocky creek, Sanyanyu, is usually stable because of the elaborated root system laced through the stony, loose soil. Prior to the intense cloudbursts, there was a long period of drought in the region and the ground surface was cracked, especially the mid-slope (1200-2500 m elevation range). In addition to causing rock falls (providing more solid sliding material), the Wenchuan earthquake, barely two years earlier, deepened the bedrock crevasses. Consequently, the drought stressed vegetation cover had little ability to intercept the rainfall and dampen the peak runoff. Much of the runoff water was channelled directly into the crevasses and deepened the shear zone. As the runoff water flowed down slope, it progressively increased the solid material contents (as a result of entrainment) and also its ability to further entrain. This positive feedback continues and at elevation of $2500 \mathrm{~m}$, large boulders of 1 meter diameter can be picked up by the turbid mud. As water filled the crevasses, patches of soil layers up to 4 meters were made unstable and were scoured out and descended along rock creeks. The scoured was generally still dry (actually only the surface several centimetres are saturated). As it ran down the steep canyon, it further picked up debris as it travelled at $\sim 5 \mathrm{~m} / \mathrm{s}$. By the time it reached lower, gentler slopes ( 1200 m elevation), its mass had increased by one order of magnitude, but the overall water content was still low. Some parts (the finer granular components) simply came to a halt. The coarse granular material and boulders continued their motion and smashed into constructions at the mouth of the rocky creek. Subsequently, material disturbed by the slide, including wood and constructions, was washed by following slides and moved down the Sanyanyu creek, depositing debris all the way to the Bailongjiang River. This tragedy, and others in the previous rainy seasons following the Wenchuan earthquake, led to the awareness of the need to develop warning system, compile hazard maps, and adopt new legislation concerning forest practice and soil reservation, for regions on active faults.

\section{A recently developed landslide dynamics model: SEGMENT-landslide}

Because of their frequent occurrence, storm-triggered shallow landslides/debris flows have been actively studied. Empirical and descriptive landslide models have contributed much to the public awareness of landslide hazards and have led to valuable accumulated experience in identifying the key causal factors (Caine 1980; Cannon and Ellen 1985; Sirangelo and Versace 1996; Godt et al. 2006). Caine (1980) proposed the seminal rainfall intensity-duration threshold line, above which shallow landslides may occur (ID method hence forth), based on 73 landslides worldwide.

In intensity-duration thresholds, a dataset consisting of rainfall intensity $(I, \mathrm{~mm} /$ day $)$ and rainfall duration $(D, h r)$ of landslide events is first made/prepared. A scatter graph is then generated with rainfall duration as $\mathrm{x}$-axis and rainfall intensity as $\mathrm{y}$-axis. The equation of 
rainfall threshold is a power-law curve that fit the points in the scatter plot (actually a lower envelope in that is a point lies to the right upper of the curve, landslides may occur), usually take the form $I=a D^{-b}$, where $a$ and $b$ are positive constants that vary with soil, vegetation and land use.

Godt et al. (2006) suggested that landslide-triggering rainfall must be considered in terms of its relationship with antecedent rainfall. For example, a heavy rainfall event within a dry period is not likely to trigger shallow landslides, while the opposite is true for lighter rainfall within a wet period. As it directly affects soil moisture conditions, Godt et al. (2006) correctly claim that antecedent rainfall must be included in an empirical model's assessing of a rainfall's potential in causing landslide. Godt et al. (2006) therefore is a significant improvement over Caine's (1980) seminal rainfall intensity-duration threshold line approach. The antecedent rainfall index is usually defined as a red noise of the accumulative rainfall amount 3 days (for tropics) and 7 days (temperate climate zone) prior the landslide event. Recent empirical methods also compile many soil hydrological parameters by using water-balance models with little physical basis but are convenient for estimating soil moisture conditions. For example, Godt et al. (2006) uses a detailed assessment of rainfall triggering conditions, hill slope hydrologic properties, soil mechanical properties, and slope stability analyses. The accumulation of sliding material is a slow process (either rockfalls or aeolian processes or damaging erosion processes from weathering) compared with the sliding. Previous sliding will reshape the sliding material profile and may even completely remove the sliding layer. These will increase the stability of the slope and a similar rainfall amount may cause sliding on a reduced scale, or not at all. Thus, the empirical parameters ( $a$ and $b$ ) in the ID approach vary not only spatially but also temporally. In this sense, all previous ID approaches still lack the important time varying features.

A synthetic consideration of preparatory and triggering factors, however, demands a more comprehensive modeling of the physical processes involved in landslides (Costa, 1984; Iverson, 1997). The overview by Iverson (1997) suggested several criteria for dynamic landslide models, including that a model should be capable of simulating the full startmovement-spread-cessation cycle of the detached material, and should cover a wide spectrum of debris flows. With continued growth and expansion of human population, raintriggered shallow landslides increasingly result in loss of life and significant economic cost. From an ecological viewpoint, landslides are an important factor in desertification over mountainous regions because they are very effective in transferring biomass from live to dead respiring pools (Ren et al., 2009).

Along these lines of walking, there are physically-based slope stability models to simulate the transient dynamical response of pore pressure to spatiotemporal variability of rainfall (e.g., Transient Rainfall Infiltration and Grid-based Regional Slope-Stability AnalysisTRIGRS, Baum et al. 2008); commercially available numerical modeling codes for geotechnical analysis of soil, rock and structural support in three dimensions (e.g., FLAC3D, www.itascacg.com/flac3d), and fully three dimensional, full Navier-Stokes and multirheological modeling systems such as the scalable, extensible geo-fluid model, known as SEGMENT (Ren et al., 2008; Ren et al., 2009, Ren et al. 2010; Ren et al. 2011a,b).

Slope stability models are based on the following reasoning: On a sloping surface, the gravitational force can be partitioned into a component normal to the slope $\left(F_{n}\right)$, contributing to friction that resists sliding erosion, and a component parallel to the slope $\left(F_{p}\right)$ that promotes sliding. A stability parameter, $S$, is defined as $S=F_{n} \times \eta / F_{p}$, where $\eta$ is the 
internal friction coefficient. This is the general form of $S$, but there are many specific forms, based on the fact that, landslides, as the movement of a mass of rock, debris or earth downslope (Cruden 1991; Dai et al. 2002), occurs when shear stress $\left(F_{p}\right)$ is higher than shear strength (i.e., when $S<1$ ). For example, the stability factor can be defined as $\left(S \times G-C_{e f f} L \sin \alpha\right) /(\cos \alpha+\operatorname{tg} \phi \sin \alpha / S) \operatorname{tg} \alpha=C_{e f f} L+\left(S \times G-C_{e f f} L \sin \alpha\right) /(S \times \cos \alpha+\operatorname{tg} \phi \sin \alpha) \operatorname{tg} \phi$ (derivations to be detailed), where $G$ is the total weight of the sliding mass, $L$ is the slope length, $\alpha$ is slope angle (of the sliding surface), $C_{\text {eff }}$ is effective cohesion (mechanical property of soil and weathered rock), and $\phi$ is internal frictional angle (mechanical property of sliding material). If a slope is composed of several segments of sub-slopes with very different mechanical properties, this expression can be summed to obtain the gross stability of the entire slope. If the iteratively obtained $S$ is 1 , it is assumed that slope is in critical stable condition.

The stability parameter is intended to diagnose when the sliding initiate. Because only static mechanical properties are included, slope stability model does not include the sliding process and how the sliding material redistributes after sliding ceases. Two dimensional slope stability models have difficulty in implementing realistic lateral boundary conditions and cannot be applied to a regional area. Three dimensional (3-D) models allow all the known physical processes and can be applied to regional areas. The following is an outline of a recently established 3-D dynamics model for studying storm-triggered landslides.

To describe the physics involved in Figure 2, the following equations are used in SEGMENT-landslide. For the sliding material, a coupled system is solved for conservation of mass:

$$
\nabla \cdot \vec{V}=0
$$

and momentum:

$$
\rho\left(\frac{\partial \vec{V}}{\partial t}+\nabla \bullet(\vec{V} \otimes \vec{V})\right)=\nabla \bullet \sigma+F
$$

under the multiphase rheological relationships, for water, condensed mud, and wet sliding granular materials, granular viscosity parameterized as:

$$
v=\left(\mu_{0}+\frac{\mu_{1}-\mu_{0}}{I_{0} / I+1}\right) \frac{S}{\left|\dot{\varepsilon_{e}}\right|}
$$

where $\rho$ is bulk density, $\vec{V}$ is velocity vector, $\sigma$ is internal stress tensor, and $F$ the body force (e.g. gravity $\rho \vec{g})$. Here $v$ is viscosity, $S=\left(R_{k k}-\rho g(h-z)\right) / 3$ is the spherical part of the stress tensor $\sigma, \mu_{0}$ and $\mu_{1}$ are the limiting values for the friction coefficient $\mu_{,}\left|\dot{\varepsilon}_{e}\right|$ is the effective strain rate and $|\cdot| \dot{\varepsilon}_{e} \mid=\left(0.5 \dot{\varepsilon}_{i j} \dot{\varepsilon}_{i j}\right)^{0.5}, I_{0}$ is a constant depending on the local slope of the footing bed as well as the material properties, and $I$ is inertial number defined 
as $I=\left|\dot{\varepsilon}_{e}\right| d /\left(S / \rho_{s}\right)^{0.5}$, where $d$ is particle diameter and $\rho_{s}$ is the particle density. Soil moisture enhancement factor on viscosity is assumed varying according a sigmoid curve formally as Eq. (9) of Sidle (1992) but with the time decay term replaced by relative saturation.

As derivatived from Eq. (1), the prognostic equation for surface elevation, $h(x, y)$, is

$$
\frac{\partial h}{\partial t}+\left.\left(\vec{V} \bullet \nabla_{H}\right)\right|_{t o p} h-\left.w\right|_{\text {top }}=0
$$

Where $\left.X\right|_{\text {top }}$ indicates evaluation at the free surface elevation. In the case with slope movements, Eq. (4) is solved regularly to update the sliding material geometry. The $w$ terms may include sedimentation rate and entrainment rate. Once the material is entrained inside the sliding material, it changes the rheological property of the medium and is advected within the sliding material.

The viscous term in Eq. (2) implies an energy conversion from kinetic energy to heat. To make a full closure of energy, we need the following thermal equation:

$$
\rho c\left(\frac{\partial T}{\partial t}+(\vec{V} \cdot \nabla) T\right)=k \Delta T+\frac{2}{v} \cdot \sigma_{e f f}^{2}
$$

Where $c$ is heat capacity $(\mathrm{J} / \mathrm{kg} / \mathrm{K}), T$ is temperature $(\mathrm{K}), \mathrm{K}$ is thermal conductivity $(\mathrm{W} / \mathrm{K} / \mathrm{m})$, and $\sigma_{\text {eff }}$ is effective stress (Pa). The last term is 'strain heating', which is the converting of work done by gravity into heat affecting the sliding material by changing viscosity or causing a phase change. Above is the landslide component of SEGMENT-landslides. Other components are shown in Fig. 3.

To describe the full start-slide-stop cycle, we boundle internal stress tensor as

$$
\sigma=\phi+C+S \mu+\delta_{E}
$$

, where $\phi=\rho g h$ is the gravitational potential, $C$ is effective cohesion, and $\delta_{E}$ the pressure perturbation caused by earthquake or human-induced disturbances at that location. $\mu<$ $\mu_{1}=\operatorname{tg} \phi$, with $\phi$ granular repose angle. For conditions with ground water, hydrostatic pressure is usually included in $S$ for convenience. The extreme values of the middle two terms on the right hand side are the yielding strength (shear strength) of the sliding material $\tau_{f}=C+S_{f} \mu$ (with subscript ' $f$ means failure). Note that, in addition to be soil moisture and soil chemical components dependent, $C$ and $\mu$ are functions of shear stress (e.g., Schofield 2006). For unfractured bedrock, $C$ is the dominant term, usually three orders of magnitudes larger than the remaining three terms combined together. For most of the soil (except pure sandy soil), cohesion and internal friction are both important in maintaining stability slopes. For fractured rocks and sandy soils, the internal friction becomes dominant term (not necessarily larger than gravitational potential, though. But, it is the horizontal gradient of the gravitational potential that caused motion, not the bulk term). When vegetation roots are involved, the mechanical effects are included in cohesion. Note that it is the interaction of distributed roots and the surrounding soil particles, not merely the 
additive of root tensile strength and soil cohesion. In a certain way, it is like the iron web reinforcement inside concrete, except that soil moisture does not play a role in the concrete case for shear strength.

The system described by Eqs. (1-6) is most suitable for study either deep-seated rotational landslides or shallow or storm-triggered debris flows. It is also convenient to investigate the positive feedback between deforestation, land use changes, undercutting of slope for road construction and expansion of settlement areas and landslides. For example, the effects of vegetation can be fully considered in this modelling system. The weight loading is set as upper stress boundary. The hydrological effects manifest in the parameterization of viscosity (dissolve of certain chemical bonds in clay soils, effects on cohesion and internal friction for sandy soils), the pore pressure adjustments of the spherical part of the stress tensor, and (minor) changes to the loading corresponding to the soil water weight (Smith and Petley 2008). The mechanical properties of the roots are implemented in the effective cohesion. The water distribution effects of vegetation roots are parameterized in a land surface sub-model. This sub-mode provides the soil moisture conditions for the sliding submodel. These explain how antecedent rainfall influence the saturation of soil and ground water level for a vegetated slope and its instability (Crosta 1998; van Asch et al. 1999) and provide a solid basis for discussing deforestation effect on landslide and the positive feedback that lead to further deforestation. Interestingly, ID empirical approach and the slope stability models are various forms of reduced form of the above equation set. For example, if the time dependence is neglected and three dimensional topography reduced to only including $x-z$ plane, the governing equations can be written as (in component form):

$$
\left\{\begin{array}{l}
\frac{\partial \sigma_{x x}}{\partial x}+\frac{\partial \sigma_{x z}}{\partial z}=0 \\
\frac{\partial \sigma_{x z}}{\partial x}+\frac{\partial \sigma_{z z}}{\partial z}-\rho g=0
\end{array}\right.
$$

Further simplify the slope geometry to be of constant bedrock slope (a) and uniform sliding material thickness (thus, surface slope also is $\alpha$ ), the volume integration of equations (7) and (8) yield

$$
\begin{aligned}
& \left(G-C_{e f f} L \sin \alpha / S+u \times \operatorname{tg} \phi \sin \alpha / S-\Sigma_{v}\right) /(\cos \alpha+\operatorname{tg} \phi \sin \alpha / S) \times \sin \alpha- \\
& \left(C_{e f f} L+\left\langle\left(G-C_{e f f} L \sin \alpha / S+u \times \operatorname{tg} \phi \sin \alpha / S-\Sigma_{v}\right) /(\cos \alpha+\operatorname{tg} \phi \sin \alpha / S)-u\right\rangle \times \operatorname{tg} \phi\right) / S \\
& \times \cos \alpha+\delta E+\Sigma_{h}+u=0
\end{aligned}
$$

where $u$ is the hydrostatic pressure from ground water, $\Sigma_{v}$ is the net vertical support at top and toe (determined by boundary conditions), $\Sigma_{h}$ is the horizontal support evaluated at top and toe, and $\delta E$ is the horizontal force exerted during earthquake. Eq. (9) indicates that slope stability is influenced by various factors, such as slope gradient $(\alpha)$, soil properties (implicit in $G, C_{\text {eff }}$ and $\alpha$ ), ground water table and geomorphology ( $u$ and the boundary conditions). As for triggering mechanism, it not only include the storm trigger (excessive rainfall), but also the earthquake and volcanic activity $(\delta E)$.

In the case without ground water and no effects of earthquake, taken the form 


$$
\begin{aligned}
& \left(S \times G-C_{e f f} L \sin \alpha\right) /(\cos \alpha+\operatorname{tg} \phi \sin \alpha / S) \operatorname{tg} \alpha= \\
& C_{e f f} L+\left(S \times G-C_{e f f} L \sin \alpha\right) /(S \times \cos \alpha+\operatorname{tg} \phi \sin \alpha) \operatorname{tg} \phi
\end{aligned}
$$

, as discussed in the review of slope stability model in the previous subsection.

Similarly, rainfall intensity-duration methods (IDs) based on the soil moisture sensitivity of the resistive terms (the middle two terms on the right hand side of Eq. (6)). Sliding material are a structured mixture, with particular spacing patterns and arrangements, of solid particles, pore water and, in some cases, cementitious material accumulated at particleparticle contacts. In addition to factors such as the electrical charge of the particles, and the chemistry of pore water, the chemical bonds are the key to the soil yield strength. As an example, there are the cementation-particles connected through a solid substance, such as recrystallized calcium carbonate formed in dry climate when seeping water experience new environments of high $\mathrm{pH}$ value and (or) the solvent get evaporated, as mentioned in Section 1. Soil water, especially of acidic $\mathrm{pH}$ value $(<6)$, can dissolve these chemical bonds. Increased pore pressure also tends to reduce the effective spherical pressure $(S)$ and reduces the yield strength of the sliding material. Comparatively, the extra loading of the water mass is insignificant for increasing slope instability. Unfortunately, IDs do not follow a processed modelling of the relationship. Rather, they have empirical/statistical relationship constructed between precipitation and occurrence of sliding. In addition to shortcomings already discussed in the previous section, current IDs do not take rain water acidity and soil profile properties into account. The empirical parameters therefore are sensitive to changes in climate and soil/vegetation/land use.

By implementing the three dimensional dynamics and the known soil physics/chemistry, SEGMENT-landslide is a recently developed and extensively tested mechanistic, processbased modeling system for monitoring and predicting storm-triggered landslides and their ecosystem implications. It is a tool for investigating the roles of triggering factors in sliding, and offers a unique opportunity for regional scale assessment. In SEGMENT, landslides are simulated using a full three dimensional Navier-Stokes solver. This is necessary because, as a mechanism for releasing unevenly concentrated stress, landslide occurrence at a specific location affects the stability of adjacent areas. 'Legacy effects' (Casadei et al. 2003) is one example. While possibly missing landslides without historical precedent, many current empirical and theoretical procedures also tend to over-predict the area that may fail in a given rainstorm (Casadei et al. 2003; Wooten et al. 2008; Y. Hong and Z. Liao 2010, personal communication). Over-estimation occurs because many empirical models employ indices based on historical events. However, the occurrence of a slide, by releasing the stress buildup, makes the surrounding area more stable and less likely to experience future sliding.

There are situations when previous landslides do assist subsequent landslides. Individual landslides transform limited amounts of potential energy into heat (Eq. (5)). Sliding can cause intense heating inside the material, especially near the bottom. This can be a positive feedback mechanism which accelerates sliding through further reduction of the shear band of loose granular material strength. However, in the case of earthquakes, the heat released by thousands of simultaneous landslides is significant enough to interact with local convective processes. The intense storms that follow may cause widespread landslides in the same area. This is well illustrated by the Wenchuan earthquake, which induced over 
5000 landslides and $\sim 3600$ rock falls. The massive amount of potential energy was transferred into heat and enhanced local convection. The following storms incurred $\sim 358$ debris flows, resulted in a direct economic loss of near \$US60 billion. SEGMENT thus simultaneously solves the thermal equation, the dynamic equations and the surface kinematic (continuity) equations.

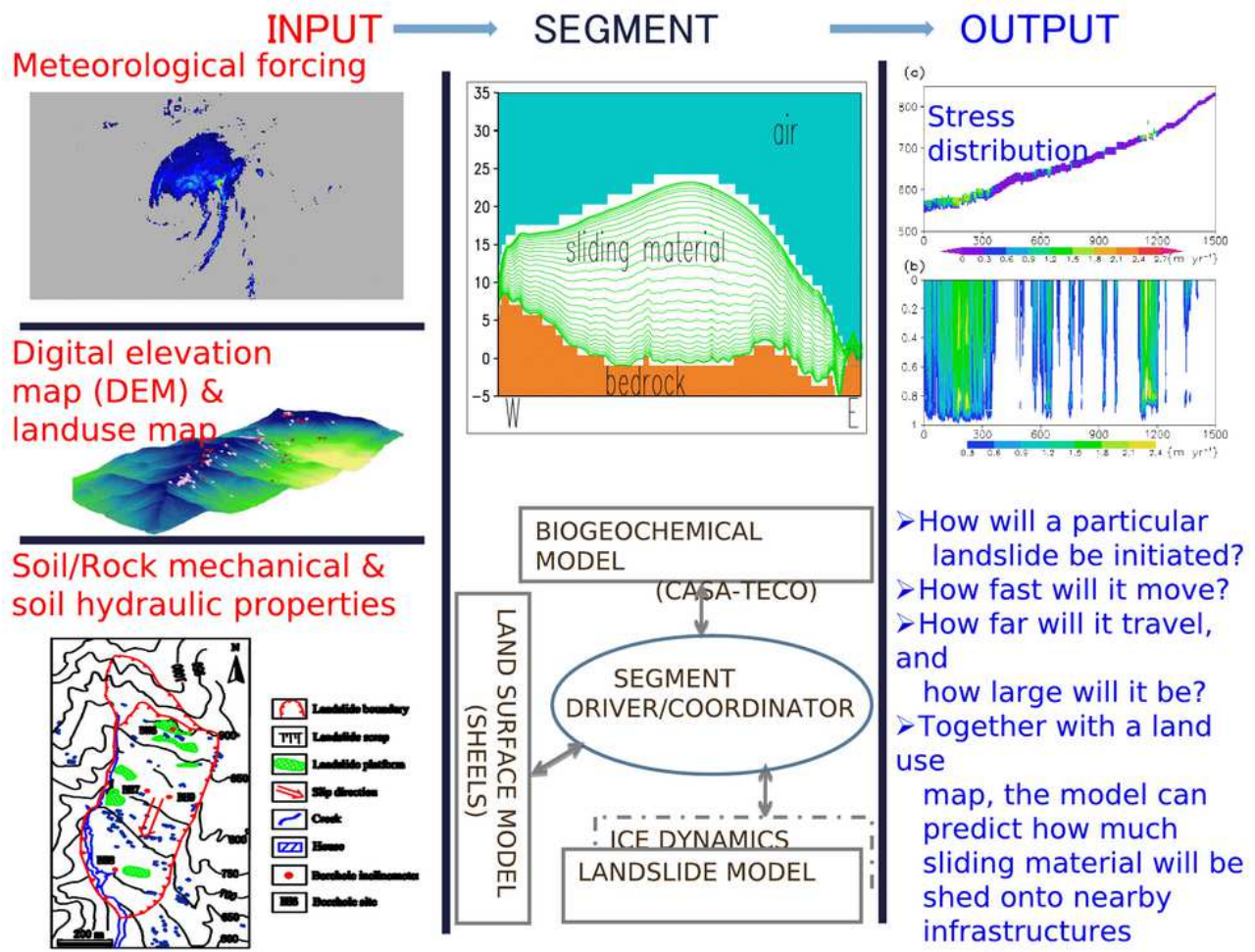

Fig. 3. Conceptual framework of SEGMENT-landslide for the projection of storm-induced landslides. The numerical techniques, model physics, input and output parameters are described in Ren et al. (2010b). The model has wide applications in many other geophysical flows including glaciers and ice-sheets, snow and mud avalanches, soil and coastal erosion, sea level change following ocean bottom tsunami, and pyroclastic flows such as magma from volcanic eruptions. The land surface model component considers hydrological processes of soils and vegetation. The mechanical properties of roots and the biomass loading also are implemented in the landslide model component.Adapted from Ren et al. 2011a.

SEGMENT, because it synthetically simulates landslides over a continuous regional area, can, in principle, minimize the false-alarm tendency of most empirical procedures. Against the 2007 wild fire-burn background, using the observed precipitation, SEGMENT simulated the landslide cases during year 2008 for a region with documented landslides (Ren et al. 2011b). Inserting the landslide model component into a scalable and extensible system (Fig. 3) also makes implementation of newly identified physical processes more convenient. This 
advantage is apparent in a recent simulation of Zhouqu landslides, where SEGMENT satisfactorily demonstrated why rainfall intensity is a critical factor affecting slope stability for cracked slopes.

For investigating environmental issues, the landslide model is inserted into the generalized scalable, extensible modelling system (SEGMENT). To illustrate the viability of SEGMENTlandslide, a case study is presented of a landslide in Yanjiashan of Hubei province, China.

\section{Case study for the Yangjiashan creeping slope}

SEGMENT-landslide uses the data typically required by a sophisticated land surface scheme. In addition to a surface elevation map and bedrock topography, the model also requires as input various geo-mechanical parameters such as cohesion, angle of repose (dry), density, porosity, field capacity, and saturated hydraulic conductivity. SEGMENTlandslide also requires a vegetation weight mask and a root distribution profile.

Detailed geological surveys are conducted only for areas with important infrastructure in danger of destruction by natural hazards. Fortunately, we have access to one such geological dataset for a small region along the Qingiiang River, a tributary of the Changjiang River. The Yangjiashan creeping slope (YC) in China, is located at $29^{\circ} 50^{\prime} \mathrm{N}$ and $109^{\circ} 14^{\prime} \mathrm{E}$ (see Fig. 4). In addition to a recently detailed geological map, we also performed an engineering study of the soil and rock profiles from bore-hole drilling, extracting soil samples for laboratory testing (Table 1), and continuous displacement measurements within the creeping zone (Fig. 5). The shear strengths of the various materials present in the region also have been obtained. Both drained and non-drained shearing tests are carried out on the soil specimens (Table 1). In addition to recovering creeping zone rock and fluid for laboratory analyses, intensive downhole geophysical measurements and long-term monitoring provided the following information: the composition and geomechanical properties of active creeping zone rocks; the nature of the stresses responsible for sliding; and the role of pressurized water in controlling landslides recurrence, for field conditions with a wide dynamic range. Displacement surveys have been carried out continuously since July 2007, using the RST-IC3500 digital inclinometer. Displacement data from five boreholes (see Fig. 4, BH6-9) are analyzed in this study. The boreholes are labeled $\mathrm{BH} 6, \mathrm{BH} 7, \mathrm{BH} 8, \mathrm{BH} 8-1$, and $\mathrm{BH} 9$ (see Table 1).

The YC region has a sub-tropical moist climate, with a typical monsoonal precipitation pattern. The annual mean precipitation ranges between 1100 and $1900 \mathrm{~mm}$. This section of the Yangjiashan Mountains, because of its proximity to a dam, is well-instrumented and thus is an ideal region to verify the numerical model, which calculates the roles of pore pressure, biomass loading and root distribution, and the intrinsic friction of the stress distribution. In this region the major slides are preceded by creeping movements. Since the 1960s, the YC slope has experienced repeated failures, as a result of exceptionally heavy rainfall periods in 1960, 1980 and 1997. During a storm in July 1997, very heavy rainfall fell over 2-3 days and caused substantial erosion in one small canyon. Field studies indicate that after a major rainstorm toe-slope failure occurs first, reducing the stability of the upper slope, and the failure then moves gradually to the upper slopes. The scenario therefore is that towards the end of a heavy rain storm, a block of material was undercut by the stream and moved into the canyon, its downhill movement left an unsupported upslope block which followed the movement. This, in turn, was followed by a third block as the movement retrogressed up the slope 


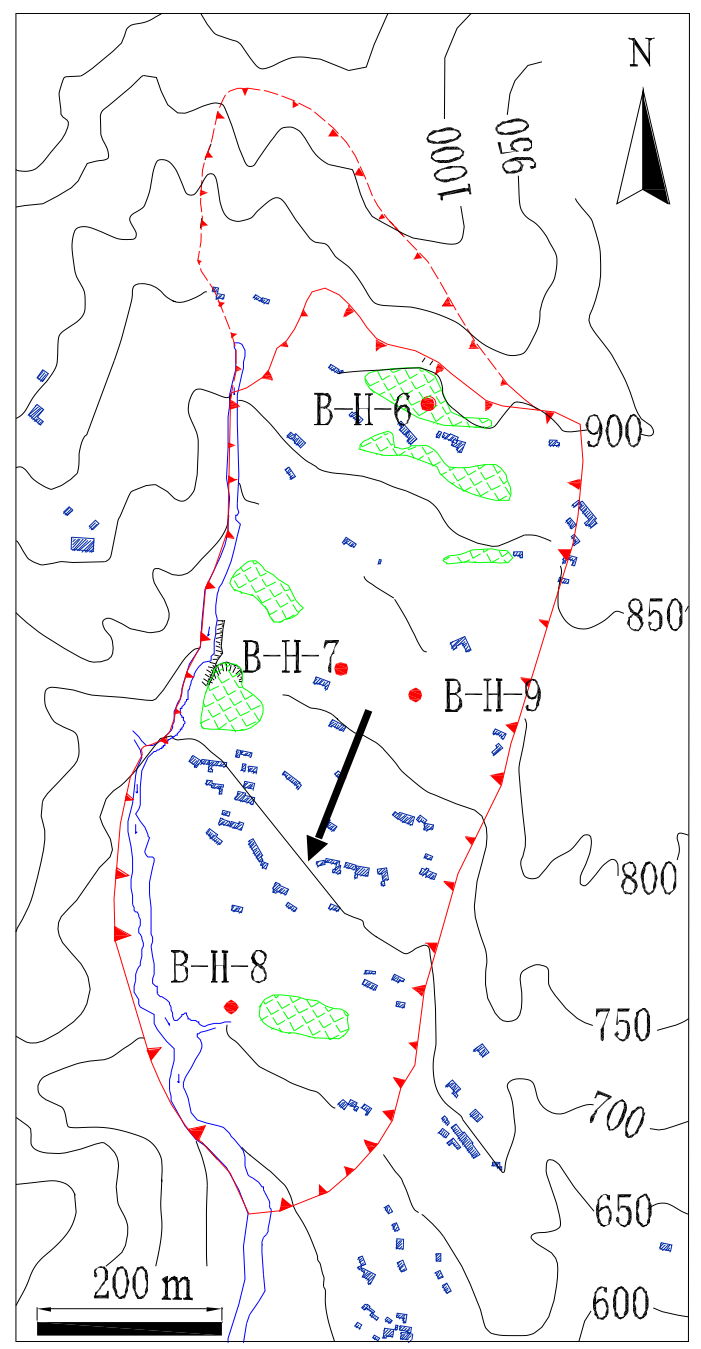

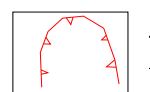

Landslide boundary

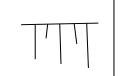

Landslide scrap

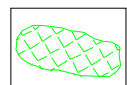

Landslide platform

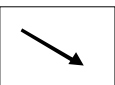

Slip direction

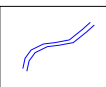

\section{Creek}

$\square$ House

- Borchole inclinometers

B- $\mathrm{H}-6$ Borehole site

Fig. 4. Topographic map of Yangjiashan Creeping (YC) slope (the upper map shows its location in China). Contours are surface elevation $(\mathrm{m})$. Borehole locations are labeled with a red circle (e.g., BH06-9). Color shading indicates surface maximum attainable creeping speeds larger than $1 \mathrm{~mm} / \mathrm{s}$, after a 50 -year recurrence storm event. The primary sliding direction (red arrow) is determined according to subsiding and swelling belts. The X- and Yaxis are distances from the SE corner $(29.9 \mathrm{~N}, 109.1 \mathrm{E})$.

The Yangjiashan community is situated on hills composed of inter-bedded siltstones and sandstones, occasionally interspersed with altered clay layers. The rocks range from highly to completely weathered at the ground surface. The weathered rocks date from the Paleozoic and Mesozoic eras, the 200-900 m thick yellowish interbedded sandstone and siltstone dates from 
the Silurian period, and the grey siltstone is from the Triassic period. The infiltration of rainfall through macro pores, which are well-developed in the soil and rock mass, plays a critical role in slope stability. The hills intersect with canyons in which increased erosion takes place during the spring and fall rainy seasons. Although many of the drainage patterns in this region have been altered by human activity, thereby increasing the slope stability, some remain unchanged, even in the inhabited areas (eastern part of the slope).

\begin{tabular}{|l|l|l|l|l|l|}
\hline & $\begin{array}{l}\text { Young's } \\
\text { modulus } \\
\mathrm{E}(\mathrm{GPa})\end{array}$ & $\begin{array}{l}\text { Poisson's } \\
\text { raio } \mu\end{array}$ & $\begin{array}{l}\text { density } \\
\rho\left(\mathrm{kg} / \mathrm{m}^{3}\right)\end{array}$ & $\begin{array}{l}\text { cohesion } \\
\mathrm{C}(\mathrm{MPa})\end{array}$ & $\begin{array}{l}\text { internal } \\
\text { friction } \\
\text { angle } \varphi\left(^{\circ}\right)\end{array}$ \\
\hline Insitu rock and soils & 0.16 & 0.24 & 2150 & 0.38 & 20 \\
\hline Slip-surface material & 0.032 & 0.32 & 1950 & 0.04 & 16 \\
\hline $\begin{array}{l}\text { Middle/lightly } \\
\text { weathered mudstone }\end{array}$ & 1.6 & 0.2 & 2600 & 1.6 & 28 \\
\hline
\end{tabular}

Table 1. Geomechanical observations and parameters obtained by field surveys and laboratory tests of saturated specimens. Rock strength and deformation properties are obtained from triaxial compression tests using INSTRON-1346. Four saturated specimens of each layer were tested. During tests, confining pressure was applied step-wise in $3 \mathrm{MPa}$ increment (i.e., 3, 6, 9, and $12 \mathrm{MPa}$ ), and vertical load are applied at displacement rate at $0.1 \mathrm{~mm} / \mathrm{s}$.

\subsection{A prediction for the Yangjiashan slope for the 2010-2019 decade}

The Triassic siltstone of $Y C$ is especially sensitive to pore pressure changes. Because of the complicated stratification, the model is initialized with five borehole soil/rock profiles (18$50 \mathrm{~m}$ depths within the granular soil mantle), with a horizontal resolution of $10 \mathrm{~m}$ in delineating the $3000 \mathrm{~m}$ by $5500 \mathrm{~m}$ simulation domain. In order to reduce spurious numerical boundary effects, the simulation domain encompasses the entire region shown in Fig. 4 . The sliding material forms a characteristic alluvial fan, that is with the down-slope section thicker than the upslope section. A thin plate splines (Burrough and McDonnell, 2004) interpolator is used to obtain a sliding mass depth distribution over the grid.

In the YC site, there are three model sub-layers to delineate the sliding mass, and one layer to represent the montmorillonite, within which sub-layers 10-12 are assumed to define the slip surface. This is further supported by the creep monitoring data (Fig. 5). This layer has the same chemical composition as the overlying layer but is physically fractured. We use 3 sub-layers to delineate the regolith layer because, although only $\sim 1 \mathrm{~m}$ deep, it is the critical layer controlling water infiltration into the creeping slide mass. As it represents granular material under high confining pressure, the viscosity of this thin bed of finer-grained materials is smaller than that of the adjacent layers. The deep underlying rock layer is divided into 7 sub-layers, with mechanical properties specified from laboratory test results.

As a link between strain and stress, viscosity Eq. (3) is the most important parameter in continuum modeling of slope movement. Under the same pressure gradient force, the smaller the viscosity, the faster the creeping rate. Non-fractured rocks have viscosity as high as $10^{19} \mathrm{~Pa} \bullet \mathrm{s}$. The creeping rate thus is minimal for non-fractured rocks. Fractured rocks (granular material), can have viscosities 10 orders of magnitude smaller, depending on confining pressure and lubrication condition (usually water content under natural conditions). A creeping curve indicates that the vertical flow shear is very large within the granular layer. Above and below the granular layer, flow shear is much smaller. For a non- 
slip lower boundary condition, the creeping rate usually is imperceptible (below $53 \mathrm{~m}$ in Fig.5) before reaching the granular layer.

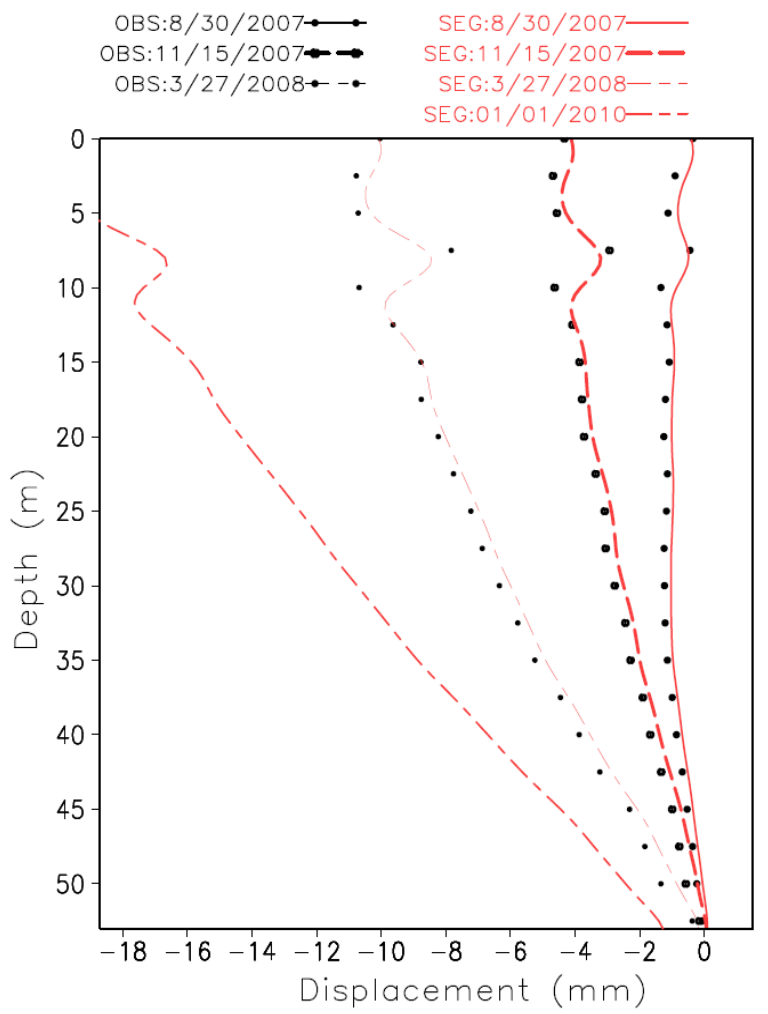

Fig. 5. The observed (markers) and modeled (lines with same style) displacement-time curves for BH8.

The absence of vegetative root strength binding soils increases susceptibility to sliding in loose soil on steep slopes during intense rainstorms (Dietrich and Perron 2006). Extra biomass loading also may contribute to slope instability during wet seasons. Ground surface biomass loading information for YC, because of its limited extent of only $\sim 20 \mathrm{~km}^{2}$, was collected by a geological survey team following a request by the first author.

Using mean annual soil moisture conditions (obtained from NCEP/NCAR reanalyses, http://www.cdc.noaa.gov/data/gridded/data.ncep.reanalysis.surfacefluxes.html), a creeping rate is simulated using the SEGMENT model near BH8 of 17, 17.2, 16.2, 8.5, 5.2 and $3.1 \mathrm{~mm} / \mathrm{yr}$ respectively at 1.5, 3, 10, 30, 40 and $45 \mathrm{~m}$ depths, agreeing well with the observed measurements. The root mean squared error, when compared with the 108 measurement data grids, is overestimated by only $0.42 \mathrm{~mm} /$ year, well within instrumental error range. The depth of the sliding surface ( $49 \mathrm{~m}$ at this location) is accurately delineated. Sliding will eventually accelerate along this plane of weakness, which is composed of highly fractured sandy shale. Interestingly, under natural conditions, the creeping speed curve is not a simple dilatant profile: there are local minima/maxima. The faster creeping locations near 
the surface in the curves are partially due to the low viscosity of this layer and partially due to the uneven surface loading in the down-slope direction of the borehole. At the time of this study, measurements are available only up to March 27, 2008.

The displacement curve is assessed for January 1, 2010 based on the climatological precipitation over the region (see Fig. 5). The basal sliding attributed to the Wenchuan earthquake of 2008 also was taken into account. Compared with the initial measurements, the shallow level displacements are as large as $18 \mathrm{~mm}$. Based on our analysis of the effects of the Wenchuan earthquake on the YC creeping slope, the creep soon will accelerate. The Wenchuan earthquake reduced the natural creeping period by at least five years. For a crevasse near $\mathrm{BH} 06$, the surface crack enlarged from 10 to $18 \mathrm{~cm}$. If the crack geometry is assumed to be constant, the crack depth almost doubles. Estimated depth changes were made of other cracks. The changes in its natural sliding cycle are obtained by comparing its creeping speed under current conditions with the pre-quake conditions. For example, after a major slope adjustment, say in 1998, it is assumed that there are no cracks due to strain. In 2008, before the earthquake, the cracks are already monitored. They all are located at model locations with large strain rates. The natural cycle is not difficult to estimate; $1 \mathrm{~mm} /$ day is the critical value for next major sliding event. Even if there is little change in the precipitation morphology, over the next ten years there likely will be significant slope movements. However, if there is an intense rainstorm with over $150 \mathrm{~mm} /$ day at any time in the future period, then sliding becomes imminent.

Three historical landslides (1960, 1980 and 1997) reported in the YC study area are separated by $\sim 20$ years (Fig. 6). In 1960 and 1997, high annual precipitation values of 1819 and 1771 $\mathrm{mm}$, respectively, were recorded. However, 1980 was relatively dry with $1200 \mathrm{~mm}$ total precipitation compared to 1600 and $1360 \mathrm{~mm}$ respectively for 1979 and 1981. Examination of the daily precipitation series from 1979 and 1980 indicates that in 1979 over 90\% of the annual precipitation occurred in the latter half of the year, with no significant precipitation before June. Although the total precipitation for 1980 is small, the heavy precipitation in January 1980 immediately following the previous year's precipitation events formed an extended wet period. There was a significant precipitation event in January, reaching a rate of $58.3 \mathrm{~mm} /$ day that lasted 4.7 hours on January 15 . As a result, the deep soil moisture $(0.23$ volume per total volume) remained relatively high for the remaining several months. What triggered the landslide was a very heavy precipitation event of a 100-year recurrence frequency, with a single day precipitation of $230 \mathrm{~mm}$ on June 11th.

For storm-triggered landslides, those precipitation events separated by less than two dry days can be considered as one single 'super' rain event. Thus, unlike many previous studies (e.g., O'Gorman and Schneider 2009), which count daily precipitation one day at a time (traditional precipitation analysis), we count those extended super-rain-events, defined as a somewhat continuous rainfall period nowhere separated by more than two consecutive dry days (rain-event analysis, Ren et al. 2011a). Figure 6 compares two methods of rainfall analyses. Using a traditional analysis, the 1997 slide does not correspond any significant daily rainfall event (>100 mm/day). However, following Ren et al. (2011), all major landslides (red arrows in Fig. 6) are triggered by rain events with higher rainfall totals. For the $Y C$, heavy precipitation is both an enhancement factor, and a determining factor, in triggering landslides. However, current observational data are less than 2 years long, which is far too short to unambiguously resolve this hypothesis. SEGMENT-landslide simulations indicate that, under long term mean soil moisture conditions, the creeping will achieve a near-surface movement rate of $0.1 \mathrm{~mm} /$ day near the head of the slope, sometime within the 
next 40 years. Ironically, this creeping rate may never have been realized during the previous half-century. It has been interrupted by heavy rain storms and, consequently, slides have occurred before this movement rate ever was reached.

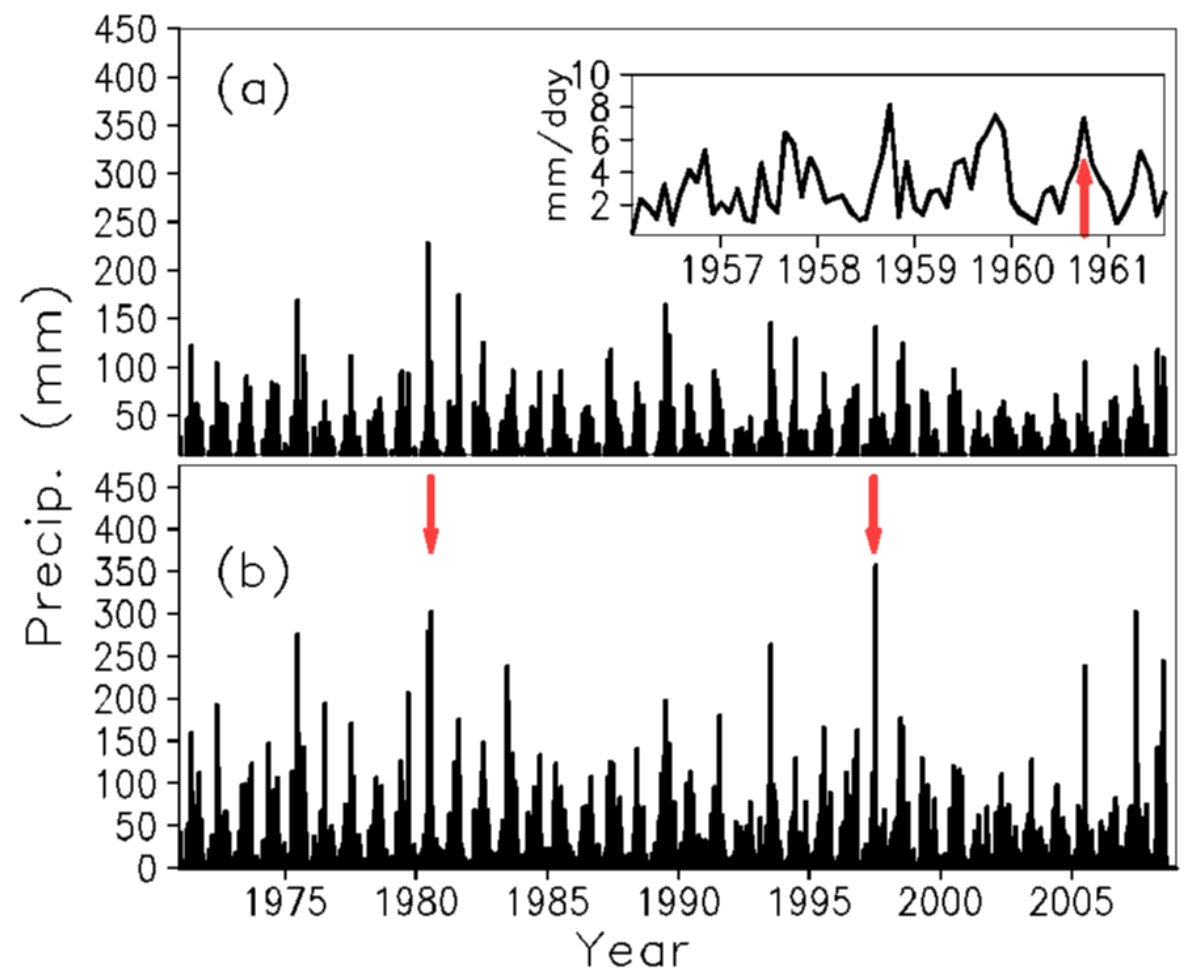

Fig. 6. (a) Daily precipitation and (b) rain event analyses, with the three major historical landslides indicated by red arrows. In panel (a) the daily rainfall time series reveals that that the 1997 event was not an intense rainfall event but was composed of two consecutive rainfall events over several days. In panel (b), rainfall totals are plotted for each rain event, by calculating the cumulative rainfall for each rain event and placing the total at the center of the start and end times. In panel (b), it is clear that both the 1980 and the 1997 events correspond to large total rainfall events. However, large rainfall totals alone do not necessarily trigger slope movements but, as discussed in the text, result from the combined effects of a number of factors. There is a lack of observed daily precipitation prior to 1970 to perform similar analyses. The inset of panel (a) is the NCEP/NCAR reanalysis monthly precipitation data. For example, the year 1960 not only had intense August precipitation, it also followed immediately after 1959, which was a very wet year.

For a storm with a 50 -year recurrence frequency $(\sim 170 \mathrm{~mm} /$ day) more than $80 \%$ of the total water mass is channeled to the sliding surface through macro-pores, so movement rates can become dramatic toward the end of such a storm. The areas of significant deformation (i.e. maximum attainable surface sliding speed greater than $1 \mathrm{~mm} / \mathrm{s}$ ) after a 50-year storm are shown in Fig. 4 (with color shades). Thus far, the geological survey team has identified at 
least 10 landslide scars and slide debris deposits, all within the color shaded areas in Fig. 4. For example, there are obvious landslide platforms near BH8 and another major one near the position labeled point ' $\mathrm{A}$ '. A shear surface exists at point ' $\mathrm{A}$ ' with a depth of about $70 \mathrm{~m}$. When water drains down to this surface, the material strength at the shear surface is reduced to its residual value. The artesian pressures along the failure surface add to the instability of the sliding mass.

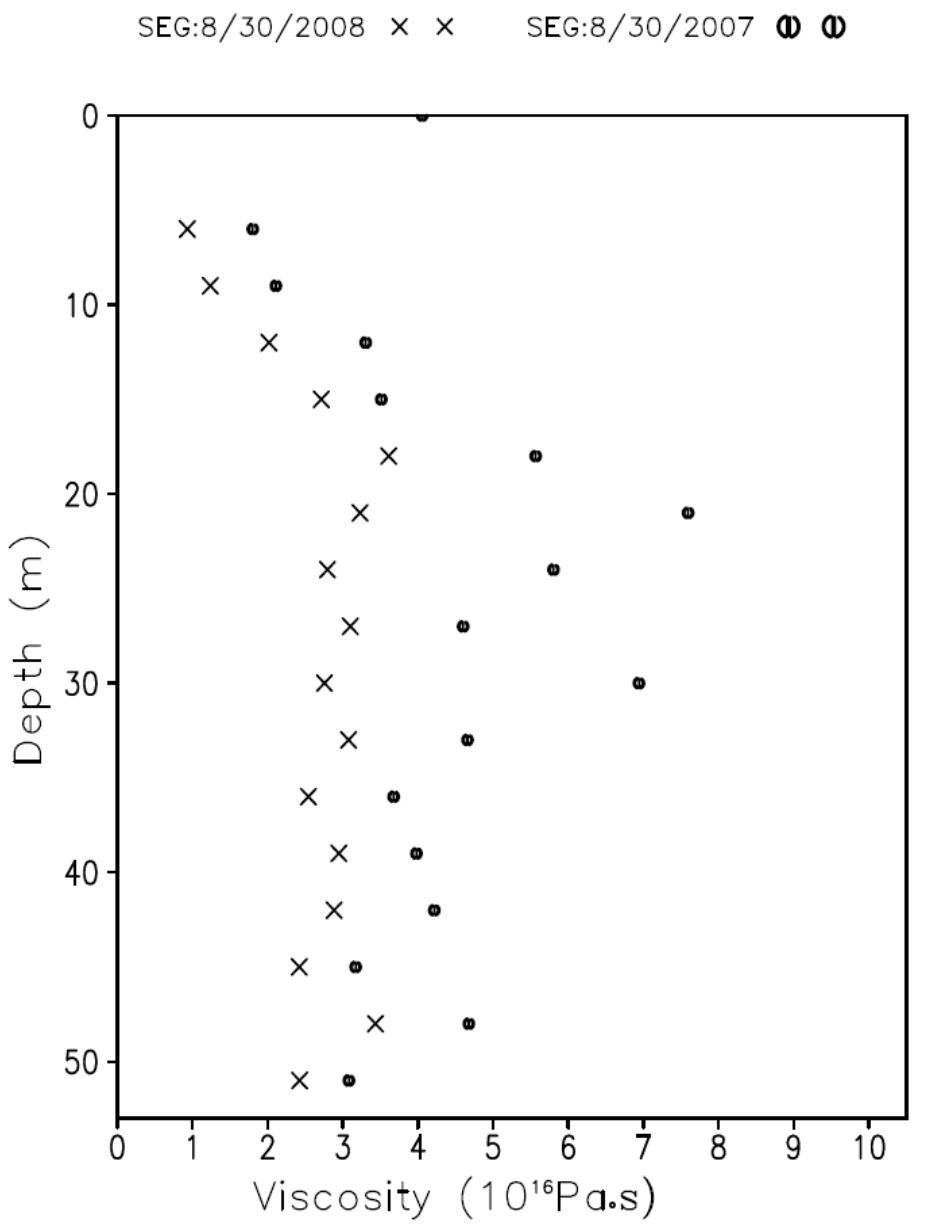

Fig. 7. Viscosity changes between August 302007 and August 30 2008, at borehole location BH8.

During heavy rainfall periods, water penetration reduces the strength of materials. In addition, hydrodynamic pressure along the slip surface further reduces stability of the sliding mass. The model simulations indicate that point ' $C$ ' is highly unstable under an extreme precipitation event. Failure will occur around this point first, triggering a failure of the upper portion. The sliding mass spreads about $50 \mathrm{~m}$ downslope and was brought to rest 
by the lateral stress from the walls of the V-shaped gully which parallels the $750 \mathrm{~m}$ elevation contour. The sliding material can become up to $20 \mathrm{~m}$ thick in the lower elevations. The accumulated material also can block the gullies and enhance infiltration of rainfall into deep layers and cause pore water pressure increases, which is a lubricating effect in the model parameterization. This is especially important for the land segment lying between the $700 \mathrm{~m}$ and $600 \mathrm{~m}$ elevation, which is where the primary human residential areas are located. To obtain additional information for verifying the model credibility for slope stability at Point ' $C$ ', several more bore-holes are required in slopes adjacent to the gully on the west bank.

In the above scenario, a volume of $6.3 \times 10^{7} \mathrm{~m}^{3}$ of soil and rock is estimated to be creeping. In retrospect, it appears landslides have been occurring in this region at intervals through history; but only part of the total creeping mass is involved in any particular landslide. Specifically, one portion may slide, causing a reduction in the stability of an adjoining portion; then, years, decades or even centuries later, a subsequent landslide will occur. As a consequence, the topography of the area is hilly and highly uneven. What determines the creeping rate of a slope is the material viscosity. We examined the modeled viscosity change near BH8 (Fig. 7). Because the rocks are heavily weathered, the viscosity is on the order of $10^{16} \mathrm{~Pa} \mathrm{~s}$, which is two orders of magnitude smaller than for the same material in an undisturbed state. So, when dealing with fractured rocks as a whole, they must be viewed as granular material. The viscosity of granular material changes as strain accumulates. In this case, the viscosity is reduced substantially with time at all levels (e.g., it is reduced by $>40 \%$ from year 2007 to 2008). This explains why the creeping tends to accelerate with time.

The SEGMENT-landslide system is valuable for monitoring creeping because it can provide a dynamical representation of changes in the strain distribution inside the sliding material. Figure 8 shows the modeled creeping velocities for January 2012. A vertical cross-section is provided along the direction of the primary sliding direction, located near the demarcation line in Fig. 4, for the current geometry and a climatological mean soil moisture conditions. Because the sliding material depth is only one-tenth of the slope dimension, for a more effective display the flow field is transformed into terrain-following sigma coordinates. The surface corresponds to $\sigma=0$ and the bottom of the sliding mass corresponds to $\sigma=1$. For clarity, the portion with flow speeds less than $0.3 \mathrm{~m} / \mathrm{yr}$ is filtered out. The formation of the local maximum speed 'core' (the band along the $\sigma=0.8$ level) near the bottom (Fig. $8 \mathrm{~b}$ ) is attributed to movement within the fractured layer. Varying the soil moisture conditions indicates that the movement of this layer is most sensitive to changes in soil moisture conditions. Any factors preventing surface water entering the ground will help reduce the acceleration of the sliding mass and delay future landslides. The landslides are sensitive to soil moisture conditions, but a qualitatively persistent feature is that the maximum strain area is located upslope, as shown by the warm color shading near $\sim 750 \mathrm{~m}$ elevation in Fig. 8a. At present there are crevasses with openings wider than $\sim 5 \mathrm{~cm}$ of horizontal displacement. That the maximum speed cores are relatively isolated indicates that the sliding surface is not fully connected. In the upcoming 10 years, the causal mechanism for major slides remains the same, namely, the storm charging of the artesian aquifer and the lubrication of the granular layer by drainage water.

To investigate the impact of possible future precipitation morphological changes over this region, 21 st century simulations are analyzed from 17 Climate General Circulation Models (CGCMS) (see Ren and Karoly 2006) under the SRES A1B (moderate) emission scenario (Nakicenovic and Swart 2000), which assumes a balanced energy source in a future of rapid economic growth. Future precipitation rates under the SREA A1B scenario are expected to 
intensify in the upcoming decades, which is in accord with the consensus of the wider climate research community (e.g., Groisman et al. 2004, Karl and Trenberth 2003). In actuality, the total rainfall amount also increases, indicating that the primary mechanism may be the increase in atmospheric vapor concentration, as described by O'Gorman and Schneider (2009).

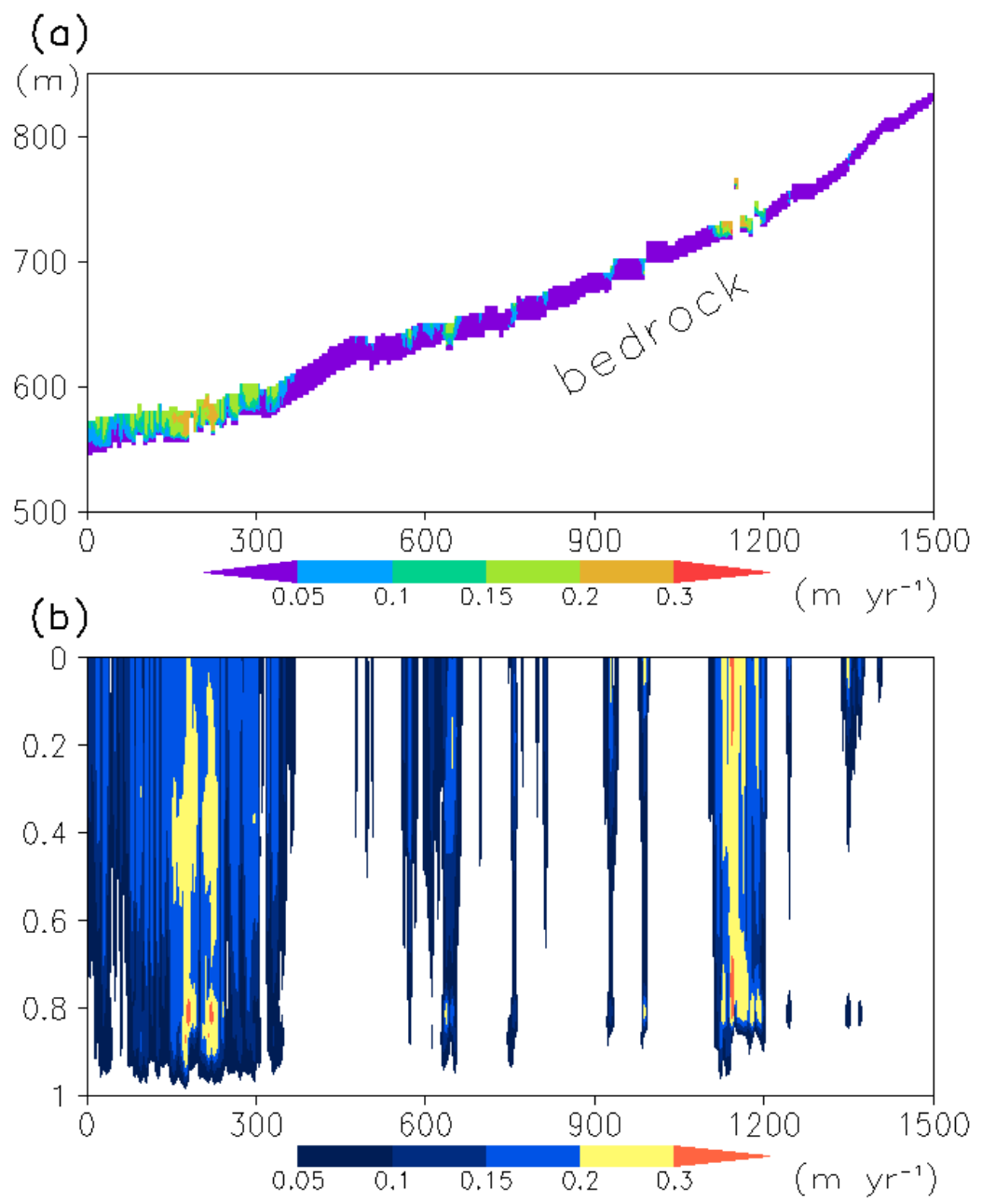

Fig. 8. Creeping speed for January 2012, within a vertical cross-section (along the red arrow in Fig. 4) under climate mean soil moisture conditions. The top panel is displayed in physical space (vertical axis is elevation; horizontal axis is distance from the origin). The bottom panel is displayed in the $\sigma$ terrain-following coordinate system. So $\sigma=0$ corresponds to the surface and $\sigma=1$ corresponds to the bottom of the sliding mass. The color shading is the magnitude of the full 3-D velocity. In panel (b) maximum cores (roughly at the $\sigma=0.8$ level) corresponding to the "creamy" basal sliding layer. 


\subsection{Discussion}

A measure of our understanding of slope sliding processes is our ability to predict the future behaviour of slopes under a range of conditions. In this study, the SEGMENT-landslide model (Ren et al., 2009; Ren et al. 2010; Ren et al., 2011a, b) successfully reproduced three historical storm-triggered landslides that occurred during the past half-century, for the Yangjiashan creeping slope (YC) in China. SEGMENT also was used to make one further, long term prediction, for the forthcoming decade, 2010-2019, which quantified the stability of the YC region and showed that slope movements will occur during the next decade and that, even more significantly, a major landslide is imminent if an intense rainstorm with over $150 \mathrm{~mm}$ of rainfall occurs at any time in that period, even in the near or immediate future.

The SEGMENT landslide modeling system has demonstrated, from numerical experiments carried out over the YC region, that it can anticipate how strain accumulates. For example, it shows how load increases with precipitation and that there is an accompanying decrease in yield strength. SEGMENT can predict when sliding, or rapid slope failure, is probable, given the available meteorological parameters, soil properties and land cover conditions.

For the YC, its particular geological constituents are the main cause of its landslide susceptibility to triggering by storm events. Heavy storms are enhancement as well as triggering factors. Our study points out an aspect that requires close monitoring because it likely is responsible for the upslope cascading of storm-triggered landslides. Model sensitivity experiments established a stability feature not investigated by the survey team. The model demonstrated that rainstorm generated instability at a given location forms the first sliding block in a sequence, by acting as a trigger for a domino-like slide that moves up the slope.

We find that increased infiltration of groundwater into the sub-surface from storms increases creeping rates dramatically for weathered slopes. For slopes experiencing repeated failure-restore cycles, increased precipitation amount and intensity under a future warming climate are the two most important factors determining long-term increases in landslide frequency.

Quantitative predictions of storm triggered landslides require a numerical modeling system like SEGMENT-landslide. However, some of the requirements of SEGMENT-landslide, especially the input and verification data, generally are not available even in current geological maps. These parameters include vegetation loading and root distributions in soils and weathered rocks. The application of the SEGMENT-landslide model to other regions is limited primarily by a lack of these high resolution input datasets. The landslide features implemented in SEGMENT-landslide, if adopted by the relevant community, hopefully will encourage the collection of such vital information in future surveys.

\section{Landslides in a future climate}

There is a considerable and expanding body of opinion which suggests that earth may suffer marked temperature increases over the next 50-100 years (Rind 1984) due to heat retention by the atmosphere caused by increased levels of the greenhouse gases (GHG) such as $\mathrm{CO}_{2}$, $\mathrm{CH}_{4}$ and oxides of nitrogen. The levels in the atmosphere have increased quite dramatically in the last 70 years and are expected to continue to rise. One consequence is an intensified hydrological cycle. Estimates of the effects vary widely but all predict some increase in storm-triggered landslides. 
The global hydrological cycle also is assumed to be intensified. However, different regions may respond very differently (Ren et al. 2011a). For example, both monsoonal regions (e.g., the Yanjiashan creeping slope located in the Asian monsoonal region) and Mediterranean regions (e.g., California) show significant increases in extreme precipitation, but the average annual precipitation changes are different. Precipitation over the Asian monsoon region increases significantly, consistent with increasing tropospheric specific humidity, as pointed out by Allen and Ingram (2002). In fact, the increase in annual mean precipitation over this region is due mainly to the shift toward heavier precipitation events. The CCSM simulated precipitation trend over southern California under the SRES A1B scenario, counterintuitively indicates that total precipitation decreases by more than $0.1 \mathrm{~mm} /$ day on an annual basis. Storms become more intense but farther apart in time, favoring a droughtflood bipolar temporal pattern as suggested by Trenberth (1999). Importantly, current climate models show strong inter-model consistency for this finding.

In landslide terms, the phenomenon has been postulated to be a potential eventuality in two different ways. One proposes that the debris flows will occur more frequently on smaller scales. The other suggestion, considered more likely by some concerns the less frequent but more disastrous outburst of storm-triggered landslides. One thing for sure is that many of regions with minor risks could be magnified if the earth's climate undergoes significant changes over the next 50-100 years as a consequence of continued burning of large amount of fossil fuels.

\section{Summary}

Natural hazards are an ever-present threat to human lives and infrastructure. The need for greater predictive capability has been identified as one of 10 Grand Challenges in Earth Sciences (NRC, 2008). As an effort toward the goal of a reliable landslide mapping and warning system, we present a modeling system (SEGMENT) that systematically estimates the potential for landslides over a regional area, rather than for a single slope. The promising performance of the model is attributable to the use of a new, fully threedimensional modeling framework based on a newly proposed granular rheology, and to the use of a land surface scheme that explicitly parameterizes the hydrological characteristics of macro-pores. Some requirements of the model, such as vegetation loading and root distribution in soils and weathered rocks, are not available even in present geological maps. Applications of SEGMENT to other regions are limited primarily by a lack of high resolution input data sets. However, the new concepts implemented in the model, if adopted by the community, may encourage the collection of such information in future surveys.

The anticipated future climate warming has influence on the occurrence of landslides caused by elevated water content in the ground. Changes in precipitation morphology are highly relevant for storm-triggered landslides and subsequent desertification, because the root system of vegetation has adapted to the current precipitation climatology and likely is not prepared for human-induced changes in climate. Under the current relatively stable astronomical boundary conditions there are natural "rhythms", whereas human induced changes are likely to transition significantly in one direction, leading to a climate state not experienced before by the existing terrestrial ecosystem. Microclimatic variations associated with slopes allow stands of an ecosystem type to exist far beyond their major zones of distribution (Chapin et al. 2002). These outliers act as important colonizing individuals during times of rapid climate change. Destroying these outlier species (transitional belts on 
Holdridge's chart) by landslide burial, accompanying extreme precipitation, may slow down ecosystem migration in accord with climate change.

Landslides are localized events. Advanced dynamical models with physical basis should be used as there is a need for prediction, rather than simply documenting the occurrence of landslides. SEGMENT-landslide is an effort in this direction. Because there are biogeochemical submodels coupled in the SEGMENT system, it also is an ideal tool for investigating the environmental consequences of landslides, including deforestation and an associated decrease in productivity.

\section{References}

Allen, M., and W. Ingram, 2002: Constraints on future changes in climate and the hydrologic cycle. Nature, 419, 224-232.

Amundson, R. V., and H. Jenny (1997), On a state factor model of ecosystem. BioScience 47, 536-543.

Baum, R. L., W.Z. Savage, and J.W. Godt (2008), TRIGRS-A Fortran program for transient rainfall infiltration and grid based regional slope-stability analysis, version 2.0: U.S. Geological Survey Open-File Report, 75pp.

BNPB, 2009. Indonesian Disaster Data and Information. Badan Penanggulangan Bencana Nasional (National Disaster Management Agency) Retrieved 21th May, 2009. http://dibi.bnpb.go.id/

Burrough, P.A., and R.A. McDonnell (2004), Principles of geographical information systems, Spatial Information Systems and Geostatistics, 333pp. Oxford University Press.

Caine, N. (1980), The rainfall intensity $\neg$ duration control of shallow landslides and debris flows. Geografisker Annaler, Series A, 62, $23 \neg 27$.

Cannon, S.H., and S. Ellen, 1985: Rainfall conditions for abundant debris avalanches. San Francisco Bay Region, California. California Geology, 38, 267-272.

Casadei, M., W. Dietrich, and N. Miller (2003), Testing a model for predicting the timing and location of shallow landslide initiation in soil-mantled landscapes, Earth Surf. Processes Landf., 28, 925-950.

Chapin III, F., P. Matson, and H. Mooney, 2002: Principles of terrestrial ecosystem ecology. Springer Science and Business Media, Inc., NY, 436p.

Costa, J. E. (1984), Physical geography of debris flows, in Costa, J. E., and Fleisher, P. J. (eds). Developments and Applications in Geomorphology: Springer Verlag, pp. 268-317.

Crosta, G. 1998. Regionalization of rainfall thresholds: an aid to landslide hazard evaluation. Environmental Geology 35 (2-3): 131-145.

Cruden, D. M., and D. J. Varnes (1996), Landslide types and processes; in, Landslides Investigation and Mitigation, A. K. Turner and R. L. Schuster, eds.: National Research Council, Transportation Research Board, Special Report 247, p. 36-75.

Cruden, DM. 1991. A Simple Definition of a Landslide. Bulletin International Association of Engineering Geology 43: 27-29.

Dai, FC, Lee, CF and Ngai, YY. (2002), Landslide risk assessment and management: an overview. Engineering Geology 64 (1): 65-87.

Dietrich, W. E., and J. T. Perron (2006), The search for a topographic signature of life. Nature, 439, 411-418. 
Godt, J., R. Baum, and A. Chleborad (2006), Rainfall characteristics for shallow land-sliding in seattle, Washington, USA, Earth Surf.Processes Landforms, 31, 97-110.

Groisman, P., R. Knight, T. Karl, D. Easterling, B. Sun, and J. Lawrimore (2004), Contemporary changes of the hydrological cycle over the contiguous United States trends derived from in situ observations. J. Hydrometeorology, 5, 64-85.

Iverson, R. (1997), The physics of debris flows. Review of Geophysics, 35, 245-296.

Karl, T., and K. Trenberth (2003), Modern Global Climate Change. Science, 302, 1719-1723.

Matson, P.A., C. Volkmann, K. Coppinger, and W.A. Reiners (1991), Annual nitrous oxide flux and soil nitrogen characteristics in sagebrush steppe ecosystems. Biogeochemistry, 14, 1-12.

Nakicenovic, N., and R. Swart (eds.) (2000), Special report on emissions scenarios (SRES). Cambridge University Press, Cambridge and New York, 612pp.

NRC, 2008: Origin and Evolution of Earth: Research Questions for a Changing Planet. National Academy Press, 137 pp.

O'Gorman, P., and T. Schneider (2009), The physical basis for increases in precipitation extremes in simulations of 21st century climate change. PNAS, 106, 14773-14777.

Ren, D., R. Fu, L. M. Leslie, and R. Dickinson (2011a), Predicting storm-triggered landslides. BAMS. DOI: 10.1175/2010BAMS3017.1.

Ren, D., R. Fu, L. M. Leslie, and R. Dickinson (2011b), Modeling the mudslide aftermath of the 2007 southern California wildfires. J. Natural Hazards. DOI: 10.1007/s11069010-9615-5.

Ren, D., R. Fu, L. M. Leslie, R. Dickinson, and X. Xin, 2010: A storm-triggered landslide monitoring and prediction system: Formulation and case study. Earth Interactions. Paper 12 of Volume 14.

Ren, D., J. Wang, R. Fu, D. Karoly, H. Yang, L. M. Leslie, C. Fu, and G. Huang (2009), Mudslide caused ecosystem degradation following Wenchuan earthquake 2008. GRL,36, doi:10.1029/2008GL036702.

Ren, D., L. M. Leslie, and D. Karoly (2008), Mudslide risk analysis using a new constitutive relationship for granular flow, Earth Interactions, 12, 1-16.

Ren, D., and D. Karoly (2006), Comparison of glacier-inferred temperatures with observations and climate model simulations. Geophysical Research Letters, 33, L23710.

Rind, D. (1984), The influence of vegetation on the hydrological cycle in a global climate model. Climatic processes and climate sensitivity. J. E. Hansen and T. Takahashi, Eds., Amer. Geophys. Union, Washington, DC, 73-91.

Schofield, A. N., and T. Telford, 2006. Disturbed soil properties and geotechnical design, ISBN 0-7277-2982-9.

Selby, M.J. (1993), Hillslope Materials and Processes. Oxford university press, Oxford, UK.

Sidle, R. C. (1992), A theoretical model of the effects of timber harvesting on slope stability. Water Resources Research, 28, 1897-1910.

Sirangelo, B., and P. Versace, 1996: A real time forecasting model for landslides triggered by rainfall. Meccanica, 31, 73-85.

Smith, K and D. Petley (2008), Environmental Hazards: Assessing Risk and Reducing Disaster, Fifth Edition. Routledge, London, 414p. ISBN 0-203-88480-9

Trenberth, K., 1999: Conceptual framework for changes of extremes of the hydrological cycle with climate change. Clim. Change, 42, 327-339. 
Van Asch, T., and Van Beek, J. 1999. A View on Some Hydrological Triggering Systems in Landslides. Geomorphology 30 (Elsevier Science): 25-32.

Wooten RM, K. A. Gillon, A. Witt, R. Latham, T. Douglas, J. Bauer, S. Fuemmeler, and L. Lee, 2008: Geologic, geomorphic, and meteorological aspects of debris flows triggered by Hurricanes Frances and Ivan during September 2004 in the southern Appalachian Mountains of Macon county, North Carolina (southeastern USA). Landslides, 5,31-44. 


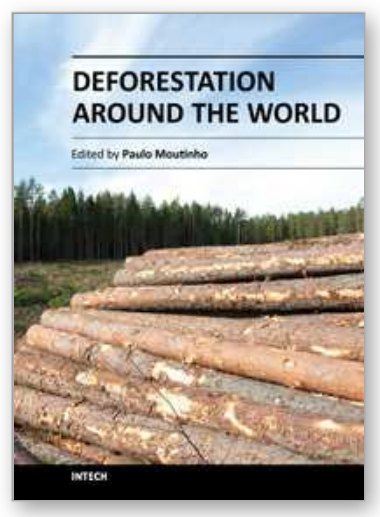

\author{
Deforestation Around the World \\ Edited by Dr. Paulo Moutinho
}

ISBN 978-953-51-0417-9

Hard cover, 372 pages

Publisher InTech

Published online 30, March, 2012

Published in print edition March, 2012

Deforestation and forest degradation represent a significant fraction of the annual worldwide human-induced emission of greenhouse gases to the atmosphere, the main source of biodiversity losses and the destruction of millions of people's homes. Despite local/regional causes, its consequences are global. This book provides a general view about deforestation dynamics around the world, incorporating analyses of its causes, impacts and actions to prevent it. Its 17 Chapters, organized in three sections, refer to deforestation impacts on climate, soil, biodiversity and human population, but also describe several initiatives to prevent it. A special emphasis is given to different remote-sensing and mapping techniques that could be used as a source for decision-makers and society to promote forest conservation and control deforestation.

\title{
How to reference
}

In order to correctly reference this scholarly work, feel free to copy and paste the following:

Diandong Ren, Lance M. Leslie and Qingyun Duan (2012). Landslides Caused Deforestation, Deforestation Around the World, Dr. Paulo Moutinho (Ed.), ISBN: 978-953-51-0417-9, InTech, Available from: http://www.intechopen.com/books/deforestation-around-the-world/landslides-caused-deforestation

\section{INTECH}

open science | open minds

\section{InTech Europe}

University Campus STeP Ri Slavka Krautzeka 83/A 51000 Rijeka, Croatia Phone: +385 (51) 770447

Fax: +385 (51) 686166 www.intechopen.com

\section{InTech China}

Unit 405, Office Block, Hotel Equatorial Shanghai No.65, Yan An Road (West), Shanghai, 200040, China 中国上海市延安西路65号上海国际贵都大饭店办公楼405单元 Phone: +86-21-62489820

Fax: +86-21-62489821 
(C) 2012 The Author(s). Licensee IntechOpen. This is an open access article distributed under the terms of the Creative Commons Attribution 3.0 License, which permits unrestricted use, distribution, and reproduction in any medium, provided the original work is properly cited. 